\title{
A Measurement of Attitude toward Working with Robots (AWRO): A Compare and Contrast Study of AWRO with Negative Attitude toward Robots (NARS)
}

\author{
Lionel P. Robert Jr. ${ }^{[0000-0002-1410-2601]}$ \\ School of Information and Robotics Institute \\ University of Michigan, Ann Arbor MI 48109, USA \\ lprobertaumich.edu
}

\begin{abstract}
Organizations are increasingly relying on a workforce that includes humans and robots working collaboratively. Yet, many humans are reluctant to work with robots. To help identify and predict who is likely to want to work with a robot, this paper introduces a new scale called attitude toward working with a robot (AWRO). The author conducted a study to assess the AWRO scale's construct validity and reliability along with its predictive power in relation to NARS. The AWRO scale was administered to 220 restaurant employees. AWRO demonstrated good construct validity and reliability and was also much more predictive of worker outcomes than NARS. Results of this study have implications for a workforce that includes humans and robots working collaboratively.
\end{abstract}

Keywords: negative attitude toward robots, attitude toward working with a robot, NARS, AWRO, working with robots.

\section{$1 \quad$ Introduction}

Organizations are increasingly relying on a workforce that includes humans and robots working collaboratively. Yet, many humans are reluctant to work with robots [1]. Currently, the negative attitude toward robots (NARS) scale is often used to help assess an individual's attitude toward robots [2]. NARS is a general attitude measure designed to assess an individual's overall attitude toward robots [3]. Prior literature on attitudes suggests that the more specific an attitude measure, the more predictive it will be in assessing someone's future behavior $[4,5]$. This suggests that a measure designed specifically to assess an individual attitude toward working with a robot would be better at assessing how likely it would be for someone to want to engage in collaborative work with the robot.

To address the problem of creating new scales that are more specific to a workplace setting, the author had several goals in this paper. First, this paper introduces a new set of scales to measure an individual's attitude toward working with a robot (AWRO). To test this measure, the author administered the AWRO scale to 220 restaurant employees. Second, the study assessed the reliability and the discriminant and convergent validity of this new scale alongside the existing NARS scale. Finally, this study compared the predictive ability of this new scale on work outcomes against the existing NARS 
scale. In all, this study examined the impact of the AWRO scale to predict someone's willingness to work with a robotic co-worker.

This paper contributes to the human-robot interaction literature in several ways. First, it introduces a new measure that can help determine who is and who is not likely to want to work with a robot. Practically, this could aid in the selection, hiring and assigning of employees who are likely to enjoy and be successful working with robots. Theoretically, this new scale could help scholars better control for individual differences likely to impact human-robot interactions. Second, this study examined the incremental value of this new scale alongside NARS. This allowed for direct comparison with regard to predictability while also assessing measurement validity between the scales.

\section{Background}

\subsection{Working with Robots}

Humans are increasingly being asked to work collaboratively with robots. Human-robot work collaboration (HRWC), where humans and robots work side by side to complete work, is expected to increase [1]. This work arrangement allows repetitive and tedious tasks to be off-loaded to robots. This has the potential to help reduce the physical injuries associated with repetitive motion [6]. This also has the benefit of freeing humans to focus on other tasks that cannot be easily performed by robots [7]. This explains why robots are being deployed in assembly lines, order fulfillment centers, and product inspections service centers [8]. For example, Amazon is adding 15,000 robots a year to work with employees in its 20 fulfillment centers [9]. Robots are projected to replace as much as half the workforce in 10-20 years [7, 10,11].

Organizations are left with the challenge of integrating humans and robots into a cohesive workforce. This challenge is made harder because some humans are reluctant to work with robots. This is, in part, because some workers are concerned about the loss of their future employment to robots [12]. In other cases, humans are just apprehensive or fearful of working with a robot [13]. Organizations are seeking ways to identify workers who might be more willing to work with robots. Considering the importance of human and robot work collaboration, more theoretical and empirical work is needed $[1,13]$.

\section{$2.2 \quad$ Attitudes}

Attitudes are an individual's predisposed favorable or unfavorable feelings about a particular person, place, thing, event or action [14]. As such, attitudes not only represent but also influence an individual's thoughts and behavior $[14,15]$. This explains why attitudes feature prominently in many social-psychological theories, such as the Theory of Planned Behavior [14]. Generally, the more favorable an attitude an individual has toward another person, place, thing, event or action, the more likely that individual is to engage with the other person, place, thing, event or action. 


\subsection{Negative Attitudes Towards Robots Scale (NARS)}

Nowhere has this been truer than in understanding human interactions with technology $[15,16]$. Favorable attitudes toward a technology indicate that someone is more likely to use or accept that technology $[15,16]$. Differences in individuals' attitudes regarding technology can be profound [17]. Several prominent technology acceptance models include attitude as a key construct [16].

NARS is one measure of a person's attitude toward robots used to predict when someone would prefer or not prefer to interact with robots [2, 18]. Nomura et al. [2] developed NARS in Japan to measure general human negative attitudes toward robots. Since then, NARS has been adapted and widely used to measure human attitudes toward robots [3]. In many studies, NARS has been employed as control variable to take into account that some individuals are more or less receptive to robots $[13,18]$.

\subsection{Attitude toward Working with Robots (AWRO)}

Although attitude has been recognized as a key predictor of behavior, scholars have distinguished between general and specific attitudes [18]. General attitudes refer to favorable or unfavorable feelings toward a category of people, places, things, events or actions, whereas specific attitudes are more narrowly focused on favorable or unfavorable feelings toward a particular instance within a category of people, places, things, events or actions [19]. General attitudes are more predictive of general tendencies to engage in behaviors involving a broad category of people, places, things, events or actions, whereas specific attitudes are better predictors of behaviors involving a particular instance within one of those categories [see 4, 5].

The differences between general and specific attitudes are not absolute but are instead relative. For example, NARS can be considered a measure of an attitude toward a particular technology. In this way, NARS can be considered a specific measure of a general attitudinal measure of a specific technology. Yet, in another way, NARS could be viewed as a general measure of someone's attitude toward a robot. Attitude toward working with a robot represents a specific instance of a more general category of interacting with robots. A more specific measure of attitude toward working with a robot might provide a much predictive measure for organizations. To address this gap, the author proposes a specific measure of attitude toward robots in reference to work.

\section{$3 \quad$ Method and Analysis}

\subsection{Participants}

The participants were 220 restaurant employees. The participants' ages ranged from 18 to 67 years, with a mean of 36.8 years and a standard deviation of 12.3 years. The majority of the employees were females, $64.5 \%$, followed by males, $34.5 \%$, one 
transgender male, $0.5 \%$, and one who preferred not to answer, $0.5 \%$. The average restaurant employee worked 8.8 hours per day, with a standard deviation of 2.5 hours. The average restaurant employee had been working in the restaurant industry for 9.5 years.

\subsection{Data Collection}

This sample was obtained with the help of a panel service company via Qualtrics. The survey was administered online using a web-based platform and the participants were assured that their responses were confidential and that only the researcher would see their responses.

\subsection{Measurements}

Control Variables. There were five control variables: age, gender, marital status, work hours per day, and time in the profession. Gender and marital status were treated as categorical variables. The specific categories are listed in Table 1.

Table 1. Control Variables.

\begin{tabular}{lll}
\hline & Label & $\mathrm{N}$ \\
\hline Gender 1 & Female & 142 \\
Gender 2 & Male & 76 \\
Gender 3 & Transgender Female & 0 \\
Gender 4 & Transgender Male & 1 \\
Gender 5 & Not listed & 1 \\
Gender 6 & Prefer not to answer & 1 \\
Marital Status 1 & Single (Never Married) & 89 \\
Marital Status 2 & Married or domestic relationship & 100 \\
Marital Status 3 & Widowed & 3 \\
Marital Status 4 & Divorced & 24 \\
Marital Status 5 & Separated & 4 \\
\hline
\end{tabular}

Independent Variables. The two independent variables were AWRO and NARS. The items for both measures are shown in Table 2 .

Table 2. Measurement Items for NARS and AWRO.

\begin{tabular}{ll}
\hline NARS & AWRO \\
\hline I would feel uneasy if I were given a job where & I am someone who would enjoy working with \\
I had to use robots. (NARS 1) & a robot. (AWRO 1) \\
$\begin{array}{ll}\text { I would feel nervous operating a robot in front } \\
\text { of other people. (NARS 2) }\end{array}$ & I am someone who would be happy to receive \\
work from a robot. (AWRO 2)
\end{tabular}


I would hate the idea that robots or artificial intelligences were making judgments about things. (NARS 3)

I am concerned that robots would be a bad influence on children. (NARS 4)

If robots had emotions, I would not be able to make friends with them. (NARS 5)

I do not feel comforted being with robots that have emotions. (NARS 6)
I am someone who would find it fun to give work to a robot to perform. (AWRO 3)

I am someone who would like to collaborate with a robot to accomplish my work. (AWRO 4)

I am someone who find it fun to work with a robot. (AWRO 5)

I am someone who would prefer to work with a robot. (AWRO 6)

Dependent Variables. The two dependent variables were turnover intention from working with a robot and expected job satisfaction with working with a robot. Items for turnover intention were adapted from [20], while items for job satisfaction were adapted from [21] to represent the context of working with a robot. The items for both measures are shown in Table 3.

Table 3. Items for turnover intention and job satisfaction for working with a robot.

\begin{tabular}{ll}
\hline Turnover Intention & Job Satisfaction \\
\hline $\begin{array}{l}\text { Working with a robot would likely de/increase } \\
\text { my intention to leave my organization in the fu- }\end{array}$ & $\begin{array}{l}\text { If I had to work with a robot, I would still rec- } \\
\text { ommend this job to a good friend of mine. } \\
\text { ture. (TO1) }\end{array}$ \\
$\begin{array}{ll}\text { Working with a robot would likely de/increase } \\
\text { my intention to seek another job in another or- }\end{array}$ & $\begin{array}{l}\text { If I had to work with a robot, I would be satis- } \\
\text { fied with my job. (JS2) }\end{array}$ \\
$\begin{array}{ll}\text { Working with a robot would de/increase me } \\
\text { considering leaving my organization. (TO3) }\end{array}$ & $\begin{array}{l}\text { If I had to work with a robot, I would be gen- } \\
\text { erally happy with my job. (JS1) }\end{array}$ \\
\hline
\end{tabular}

Item reliability. The AWRO multi-item measurement scale demonstrated high reliability with an alpha of .95. Each item was also reliable, as shown in Table 4. Dropping any item would not increase the overall construct reliability.

Table 4. AWRO Measurement Item Reliability.

\begin{tabular}{ll}
\hline AWRO & Reliability if item deleted \\
\hline AWRO 1 & .93 \\
AWRO 2 & .94 \\
AWRO 3 & .94 \\
AWRO 4 & .93 \\
AWRO 5 & .93 \\
AWRO 6 & .94 \\
\hline
\end{tabular}


Discriminant and Convergent Validity. Convergent and discriminant validity were assessed using factor analysis with a varimax rotation. Table 5 shows the factor loadings for each item. Values less than .40 are not shown in the table. Except for one item, all cross-loadings were less than .40 , demonstrating discriminant validity [22]; two items had loadings less than .70, suggesting good although not great convergent validity. It should be noted that NARS demonstrated less convergent and discriminant validity than AWRO. More specifically, NARS had three items with factor loadings that fell below .60 and 1 item that fell below .70. NARS cross-loaded more with job satisfaction than AWRO.

Table 5. Factor Loadings.

\begin{tabular}{lllll}
\hline AWRO & AWRO & Turnover Intention & Job Satisfaction & NARS \\
\hline AWRO 1 & .70 & & .41 \\
AWRO 2 & .64 & & & \\
AWRO 3 & .80 & & & \\
AWRO 4 & .82 & & & \\
AWRO 5 & .76 & & & \\
AWRO 6 & .64 & & & \\
TO1 & & .92 & & \\
TO2 & & .90 & .74 & \\
TO3 & & .91 & .81 & \\
JS1 & & & .83 & .49 \\
JS2 & & & & .76 \\
JS3 & & & & .79 \\
NARS 1 & .43 & & & .76 \\
NARS 2 & & & & \\
NARS 3 & & & & \\
NARS 4 & & & & \\
NARS 5 & & & & \\
NARS 6 & & & & \\
\hline
\end{tabular}

Correlation Matrix. The correlation matrix is shown in Table 6. $\mathrm{P}$ value significance is shown by the number of asterisks, with $* \mathrm{p}<.05, * * \mathrm{p}<.01$ and $* * \mathrm{p}<.001$. As expected, NARS and AWRO were correlated.

Table 6. Correlation Matrix.

\begin{tabular}{llllll}
\hline & Mean & Std & AWRO & Job Satisfaction & NARS \\
\hline AWRO & 3.77 & 1.60 & & & \\
Job Satisfaction & 3.50 & 1.46 & $.69^{* *}$ & &
\end{tabular}




\begin{tabular}{llllll} 
NARS & 4.30 & 1.41 & $-.77^{* *}$ & $-.57^{* *}$ & \\
Turnover Intention & 4.66 & 1.43 & $-.54^{* *}$ & $-.60^{* *}$ & $.50^{* *}$ \\
\hline
\end{tabular}

\subsection{Results}

To access the predictability of AWOR against NARS, the models were analyzed using General Linear Model (GLM) in SPSS 27. The sample size for the analysis was 220 and all betas represented unstandardized regression coefficients. $P$ value significance is shown by the number of asterisks, with ${ }^{*} \mathrm{p}<.05,{ }^{* *} \mathrm{p}<.01$ and ${ }^{* * *} \mathrm{p}<.001$.

Model 1. The results in Table 7 reflect the analysis without AWRO. Results for this analysis, model 1, as shown in Table 7, explained $29 \%$ of the variance in turnover intention ( $\left.\mathrm{F}_{10,209}=7.6, \mathrm{p}<.001\right)$ and $34 \%$ of job satisfaction ( $\left.\mathrm{F}_{10,209}=9.7, \mathrm{p}<.001\right)$.

Table 7. General Linear Model 1 Results.

\begin{tabular}{lllll}
\hline & \multicolumn{2}{l}{ Turnover Intention } & \multicolumn{2}{l}{ Job Satisfaction } \\
\hline Intercept & Coef. & S.E. & Coef. & S.E. \\
Gender $=1$ & .85 & 1.5 & 6.02 & $1.5^{* * *}$ \\
Gender $=2$ & 1.85 & 1.26 & -.303 & 1.24 \\
Gender $=4$ & 1.5 & 1.26 & -.011 & 1.24 \\
Gender $=6$ & -1.04 & 1.77 & .91 & 1.74 \\
Marital Status $=1$ & .00 &. & .00 &. \\
Marital Status $=2$ & .61 & .65 & -.17 & .64 \\
Marital Status $=3$ & .57 & .65 & -.23 & .63 \\
Marital Status $=4$ & .27 & .96 & -.29 & .95 \\
Marital Status $=5$ & .33 & .68 & -.05 & .67 \\
Age & .00 &. & .00 &. \\
Work Hours per Day & -.04 & .04 & .04 & .03 \\
Time in the Profession & -.01 & .01 & -.01 & .01 \\
\hline NARS & .46 & $.06 * * *$ & -.56 & $.06 * * *$ \\
AWRO & & & & \\
\hline R-Square & .00 & .01 & -.00 & .01 \\
Adjusted R-Square & .25 & & .34 & \\
\hline F & $7.6^{* * *}$ & & $9.7^{* * *}$ & \\
\hline
\end{tabular}

Model 2. The results in Table 8 reflect the analysis with AWRO. Results for the model 2 analysis are shown in Table 8 and explained $35 \%$ of the variance in turnover intention $\left(\mathrm{F}_{11,208}=9.5, \mathrm{p}<.001\right)$ and $50 \%$ of job satisfaction $\left(\mathrm{F}_{11,208}=17.7, \mathrm{p}<.001\right)$. 
Table 8. General Linear Model 2 Results.

\begin{tabular}{lllll}
\hline & \multicolumn{2}{l}{ Turnover Intention } & \multicolumn{2}{l}{ Job Satisfaction } \\
\hline & Coef. & S.E. & Coef. & S.E. \\
Intercept & 2.23 & 1.60 & 2.92 & $1.45^{*}$ \\
Gender $=1$ & 2.81 & $1.20^{*}$ & -1.03 & 1.10 \\
Gender $=2$ & 2.64 & $1.22^{*}$ & -.84 & 1.10 \\
Gender $=4$ & .00 &. & .00 &. \\
Marital Status $=1$ & .62 & .62 & -.31 & .56 \\
Marital Status $=2$ & .58 & .62 & -.17 & .56 \\
Marital Status $=3$ & .02 & .92 & .13 & .83 \\
Marital Status $=4$ & .35 & .65 & -.09 & .59 \\
Marital Status $=5$ & .00 &. & .00 &. \\
Age & .00 & .01 & -.01 & .01 \\
Work Hours per Day & -.05 & .03 & .05 & .03 \\
Time in the Profession & -.01 & .01 & -.01 & .01 \\
\hline NARS & .19 & $.10^{*}$ & -.08 & .09 \\
AWRO & -.33 & $.08^{* * *}$ & .56 & $.07 * * *$ \\
\hline R-Square & .35 & & .50 & \\
Adjusted R-Square & .31 & & .47 & \\
\hline F & $9.5 * * *$ & & $17.7^{* * *}$ \\
\hline
\end{tabular}

Incremental Value. To assess the incremental value of the addition of AWRO, we compared both model R-squares for each dependent variable. As seen in Table 9, the addition of AWRO significantly increased the variance explained for both turnover intention and job satisfaction over and above the model without AWRO. P value significance is shown by the number of asterisks, with $* \mathrm{p}<.05, * * \mathrm{p}<.01$ and $* * * \mathrm{p}<.001$.

Table 9. Incremental value.

\begin{tabular}{lll}
\hline & $\begin{array}{l}\text { Turnover Intention } \\
\text { R-Square }\end{array}$ & $\begin{array}{l}\text { Job Satisfaction } \\
\text { R-Square }\end{array}$ \\
\hline Model 2 with AWRO & .35 & .50 \\
Model 1 & .29 & .34 \\
\hline Difference & .06 & .16 \\
$\mathrm{~F}$ & $19.57^{* * *}$ & $67.84^{* * *}$ \\
\hline
\end{tabular}

Multicollinearity. Two linear regression analyses were conducted to test for possible multicollinearity between NARS and AWRO. In both models, the variance inflation 
factor (VIF) remained 2.5 or lower. VIF values of over 4 are considered to be an indication of a moderate multicollinearity, while values over 10 are considered to be severe multicollinearity. Therefore, multicollinearity does not appear to be a problem.

\section{Discussion}

\subsection{Summary of Findings}

The goal of this research was to introduce a new measure to help determine who is likely to want to work with a robot. To that end, the research findings can be organized into two overarching findings. One, the new measure AWRO demonstrated reliability as well as discriminant and convergent validity. Two, AWRO explained additional variances in both turnover intention and job satisfaction over and above NARS. Taken together, these findings highlight the potential importance of AWRO. Next, we detail contributions to the literature, theoretical implications and study limitations.

\subsection{Contributions}

This paper contributes to the HRI literature by helping to predict who is and who is not likely to want to work with a robot. AWRO provides a much more specific measure of attitudes toward working with robots, and this measure could be deployed alongside NARS if needed. Theoretically, this new scale is likely to better help scholars control for individual differences when empirically testing their theories of work-related human-robot interactions. This is likely to lead to better assessment of such theories by accounting for more relevant context-specific individual differences.

This study also contributes to the literature by demonstrating AWRO's incremental value in the presence of NARS. That said, there were cross-loadings between AWRO and NARS. This suggests that applying one or the other might be preferred. With that in mind, we conducted an additional analysis with just AWRO, without NARS, along with the control variables in Model 2, which predicted .33 of turnover intention and .49 of job satisfaction. Model 1 in Table 7, which had NARS and not AWRO, predicted .25 of turnover intention and .34 of job satisfaction. Therefore, AWRO had a higher predictive power when it came to explaining the two work outcomes in this study.

Finally, practically AWRO can aid in the selection, hiring and assigning of employees who are likely to enjoy and be successful working with robots. Currently, organizations that are struggling to determine whom to hire or assign to collaboratively work with robots have little guidance. AWRO provides one approach to assess an employee's readiness and willingness to work with a robotic co-worker.

\subsection{Limitations}

The paper has several limitations and opportunities for future research. The study employed a cross-sectional survey approach. This allowed the study to employ a highly 
generalizable sample. Unfortunately, like all cross-sectional survey approaches, it suffers from issues of internal validity. Future research could examine the predictive power of the AWRO scale in either an experimental setting or a survey study setting that separates via time the collection of the independent variables from the dependent variable. The study asked restaurant employees to anticipate how they might feel working with a robot with regard to their turnover intention and job satisfaction. This might have more accurately reflected their attitudes if they had worked with a robot. However, future studies could possibly ask restaurant employees who have worked with a robot about their experiences relative to turnover intention and job satisfaction.

\section{Conclusion}

Collaboration with others is at the heart of many productive work arrangements [23, 24]. Robots are increasingly becoming that collaborative work partner in many new work arrangements. Nonetheless, many humans are reluctant to work with robots. This paper introduced and tested AWRO, a new work-specific scale for assessing someone's willingness to work with a robot. However, there is much to learn regarding the use of AWRO. This study is an important start in our understanding of the usefulness of AWRO. Nonetheless, future research is needed to build and expand our understanding of AWRO.

\section{References}

1. You, S., Kim, J. H., Lee, S., Kamat, V., Robert Jr, L. P.: Enhancing perceived safety in human-robot collaborative construction using immersive virtual environments. Automation in Construction 96, 161-170 (2018).

2. Nomura, T., Suzuki, T., Kanda, T., Kato, K.: Measurement of negative attitudes toward robots. Interaction Studies 7(3), 437-454 (2006).

3. Xia, Y., LeTendre, G.: Robots for future classrooms: A cross-cultural validation study of negative attitudes toward robots scale in the U.S. context. International Journal of Social Robotics (2020), https://doi.org/10.1007/s12369-020-00669-2, last accessed 2021/2/10.

4. Ajzen, I., Fishbein, M.: Attitude-behavior relations: A theoretical analysis and review of empirical research. Psychological Bulletin 84(5), 888-918 (1977).

5. Eagly, A. H., \& Chaiken, S.: The psychology of attitudes. Harcourt Brace Jovanovich College Publishers, Fort Worth, TX (1993).

6. Schneider, S., Susi, P.: Ergonomics and construction: A review of potential hazards in new construction. American Industrial Hygiene Association Journal 55(7), 635-649 (1994).

7. Esterwood, C., Robert, L.: Robots and COVID-19: Re-imagining human-robot collaborative work in terms of reducing risks to essential workers. SSRN 2021. SSRN, https://papers.ssrn.com/sol3/papers.cfm?abstract id=3767609, last accessed 2021/2/10.

8. Knight, W.: Are you ready for a robot colleague? MIT Technology Review (2015), https://www.technologyreview.com/s/541676/are-you-ready-for-a-robot-colleague/, last accessed 2021/2/6. 
9. Clark, P., Bhasin, K.: Amazon's robot war is spreading. Bloomberg (2017), https://www.bloomberg.com/news/articles/2017-04-05/robots-enlist-humans-to-win-thewarehouse-war-amazon-started, last accessed 2021/2/6.

10. Qureshi, M. O., Syed, R. S.: The impact of robotics on employment and motivation of employees in the service sector, with special reference to health care. Safety and Health at Work 5(4), 198-202 (2014).

11. Ackerman, E.: U.S. Army considers replacing thousands of soldiers with robots. IEEE Spectrum (2014), https://spectrum.ieee.org/automaton/robotics/military-robots/army-considersreplacing-thousands-of-soldiers-with-robots, last accessed 2021/2/6.

12. Webster, M.: Could a robot do your job? USA Today (2014), https://www.usatoday.com/story/news/nation/2014/10/28/low-skill-workers-face-mechanization-challenge/16392981/, last accessed 2021/2/6.

13. You, S., Robert, L.: Emotional attachment, performance, and viability in teams collaborating with embodied physical action (EPA) robots. Journal of the Association for Information Systems 19(5), 377-407 (2018).

14. Ajzen, I: Attitudes, personality, and behavior. 2nd edn. McGraw Hill International, New York (2005).

15. Robert Jr., L. P., Sykes, T. A.: Extending the concept of control beliefs: Integrating the role of advice networks. Information Systems Research 28(1), 84-96 (2017).

16. Venkatesh, V., Morris, M. G., Davis, G. B., Davis, F. D.: User acceptance of information technology: Toward a unified view. MIS Quarterly 27(3), 425-478 (2003).

17. Robert, L. P., Alahmad, R., Kim, S., Esterwood, C., You, S., Zhang, Q.: A review of personality in human robot interactions. Foundations \& Trends in Information Systems 4(2), 107-210 (2020).

18. Smith, E. R., Sherrin, S., Fraune, M. R., Šabanović, S.: Positive emotions, more than anxiety or other negative emotions, predict willingness to interact with robots. Personality \& Social Psychology Bulletin 46(8) 1270-1283 (2020).

19. Vining, J., Ebreo, A.: Predicting recycling behavior from global and specific environmental attitudes and changes in recycling opportunities. Journal of Applied Social Psychology 22(20), 1580-1607 (1992).

20. Irving, G. P., Coleman, D. F., Cooper, C. L.: Further assessments of a three-component model of organizational commitment: Generalizability and differences across occupations. Journal of Applied Psychology 82(3), 444-452 (1997).

21. Eisenberger, R., Cummings, J., Armeli, S., Lynch, P.: Perceived organizational support, discretionary treatment, and job satisfaction. Journal of Applied Psychology 82(5), 812-820 (1997).

22. Fornell, C., Larcker, D. F.: Evaluating structural equation models with unobservable variables and measurement error. Journal of Marketing Research 18(1), 39-50 (1981).

23. Robert Jr., L. P., Dennis, A. R., Ahuja, M. K.: Differences are different: Examining the effects of communication media on the impacts of racial and gender diversity in decisionmaking teams. Information Systems Research 29(3), 525-545 (2018).

24. Robert, L. P., You, S.: Are you satisfied yet? Shared leadership, trust and individual satisfaction in virtual teams. In: Proceedings of the 2013 iConference, pp. 461-466. IDEALS, Fort Worth, TX, USA (2013). 